\title{
Early Harappan interaction between Sindh and Gujarat, as evidenced by lithic tools
}

\author{
Charusmita Gadekar ${ }^{1}$, Rajesh Sasidharan Vasantha ${ }^{2}$, \\ Abhayan Girija Sasidharan ${ }^{2}$, Bhanu Prakash Sharma ${ }^{2}$, Anil Chavan ${ }^{3}$, \\ Subhash Bhandari ${ }^{3}$, Jaypalsinh M. Jadeja ${ }^{4}$
}

1. HUMANE- Human Ecology and Archaeology, Department of Archaeology and Anthropology, IMF-CSIC, Barcelona, Spain. Email: doyaldua@gmail.com

2. Department of Archaeology, University of Kerala, Thiruvananthapuram, Kerala, India.

Email: Rajesh Sasidharan Vasantha: mrajeshkeraliyan@yahoo.co.in;

Abhaya Girija Sasidharan: abhayangs@gmail.com; Bhanu Prakash Sharma: bhanu1927@gmail.com;

3. Department of Earth and Environmental Science, K.S.K.V. Kachchh University, Bhuj, Gujarat, India.

Email: Anil Chavan: asac.anil@gmail.com; Subhash Bhandari: subhashbhandari@gmail.com

4. Department of Archaeology, K.S.K.V. Kachchh University, Bhuj, Gujarat, India.

Email: jaypalsinhjadeja008@gmail.com

\begin{abstract}
:
The spread and development of the Indus Valley Civilisation, also known as the Harappan civilisation, one of the oldest civilisations of the world, is still an enigma. Indus Valley Civilisation was spread over modern day India and Pakistan. The civilisation has been divided into three phases, Early or Pre-Harappan, Mature or Urban Harappan and Post- or Late Harappan. The Urban phase is very well studied and understood. However, this phase is the culmination of a process that started much earlier. A lot of effort during recent years has led to new discoveries and clues regarding the interactions during the Early Harappan period between now politically divided areas. Unfortunately, this struggle to understand the spread of Early Harappan cultural traits between these distinct regions is one on-going and far from over.

Explorations and subsequent excavations at the site of Juna Khatiya, situated in Kachchh district of Gujarat, India have brought to light noteworthy evidence of the Early Harappan period in terms of artefacts and burials. Other than the ubiquitous pottery, these indications include a lithic blade industry comprising of various types of blades, various types of scrapers, points and associated lithic debitage. The tools are made out of locally available raw material (mostly chalcedony). However, the discovery of a few blades of chert imported from the Rohri hills (situated about $500 \mathrm{~km}$ as-the-crow-flies from Gujarat) in modern Pakistan is important. Rohri chert blades are significant since they are very distinct and easily identifiable. The wide distribution of standardised Rohri chert blades is also often regarded as a testimony to the Harappan efficiency in long distance trade and craft production. The technique used in the manufacturing of these blades is known as the crested guiding ridge, a technique not observed in Gujarat before this contact between Sindh (in modern Pakistan) and Gujarat (in modern India) developed. This paper highlights the contributions of lithic artefacts to understand the Early Harappan interactions between these two politically divided but culturally united regions.
\end{abstract}

Published by the School of History, Classics and Archaeology, University of Edinburgh ISSN: 2055-0472. URL: http://journals.ed.ac.uk/lithicstudies/ 
Keywords: crested ridge technique; lithic technology; Early Harappan interaction; Indus Valley Civilization; Pakistan; Gujarat

\section{Introduction and background}

The Indus Valley Civilisation, also known as Indus Civilisation or Harappan Civilisation, was a Bronze Age civilisation which flourished during the third millennium BCE in modern day India, Pakistan and Afghanistan (Wright 2009: 1). The civilisation has three phases, Early or Pre Harappan (c. 3300-2500 BCE), Mature or Urban Harappan (c. 2600-1900 BCE) and Late or Post Harappan (c. 1900-1300 BCE) (Shaffer 1992). It is well known for its urban planning and architecture, standardised system of weights and measures, various types of arts and crafts, extremely distinct pottery style (often employed to define a newly discovered site into a phase), metallurgy and a trade network spread over a vast geographical area.

The civilisation was discovered during late 1800s but came to be widely known after Sir John Marshall announced its discovery in the Illustrated London News on September 1924 (Lahiri 2017). After the partition of India into India and Pakistan in 1947, then well-known sites of Harappa and Mohenjo-daro fell under newly created Pakistan. Thus, most of the research during 50s, 60s and 70s in India was devoted to filling the lacuna of identifying Indus Valley Civilisation sites in India. This resulted in the discovery of a large number of sites from modern states of Gujarat, Rajasthan, Punjab, Harayana, Uttar Pradesh and Jammu and Kashmir.

The state of Gujarat has a unique chalcolithic cultural pattern. It is almost like a jigsaw puzzle where some parts are clearly defined but some are missing, leaving the puzzle incomplete. A quick look into the geography of Gujarat shows that it has been divided into three distinct physiographic zones, the mainland Gujarat, Saurashtra peninsula and the Rann of Kachchh. North Gujarat is the narrow corridor which connects mainland Gujarat with Kachchh (Mehr 1995: 3).

Two broad distinct groups of early Chalcolithic assemblage predating the Urban or Mature Harappan occupation are seen in the Gujarat. The first group comprises an assortment of Chalcollithic village farming communities (named after their type-sites) in diverse geographical regions. They show certain individuality in their ceramic industry but at the same time, show remarkable adaptive flexibility. None of these pre or non Harappan settlements, however, anticipate an urban way of life. These were small farming settlements affording flimsy structures mostly of wattle and daub or similar nondescript materials. However, they did have knowledge of copper metallurgy and produced pottery vessels and lapidary stone beads (Ajithprasad 2002). The earliest amongst these regional Chalcolithic village farming communities is from the site of Loteshwar (Figure 1), known as Anarta tradition. This site has been dated to 3700-3600 BCE by conventional radiocarbon and AMS estimation (Ajithprasad 2004; Patel 2008). Contemporary to Anarta was the Padri culture (Shinde 1992a; 1992b; Rajesh 2012: 378). Pre-Prabhas is the third important early Chalcolithic ceramic assemblage reported from the Saurashtra coast and North Gujarat dates to 2900-3000 BCE (Ajithprasad 2011).

The second group is a set of ceramic assemblages forming the Early Harappan reported from the site of Dholavira and ceramic assemblages from several burials such as from Nagwada, Santhli and Surkotda (Figure 1). These have a general resemblance with the Early Harappan ceramics reported from sites in Sindh and Baluchistan in modern Pakistan. Therefore they indicate the extension of the Early Harappan communities of that region into Gujarat prior to the Urban Harappan phase (Ajithprasad 2002). The state of Gujarat has been giving more and more evidence for the interaction between the early regional Chalcolithic 
traditions of modern India and Pakistan resulting ultimately in the development of Urban Harappan Civilisation spanning both the modern countries.

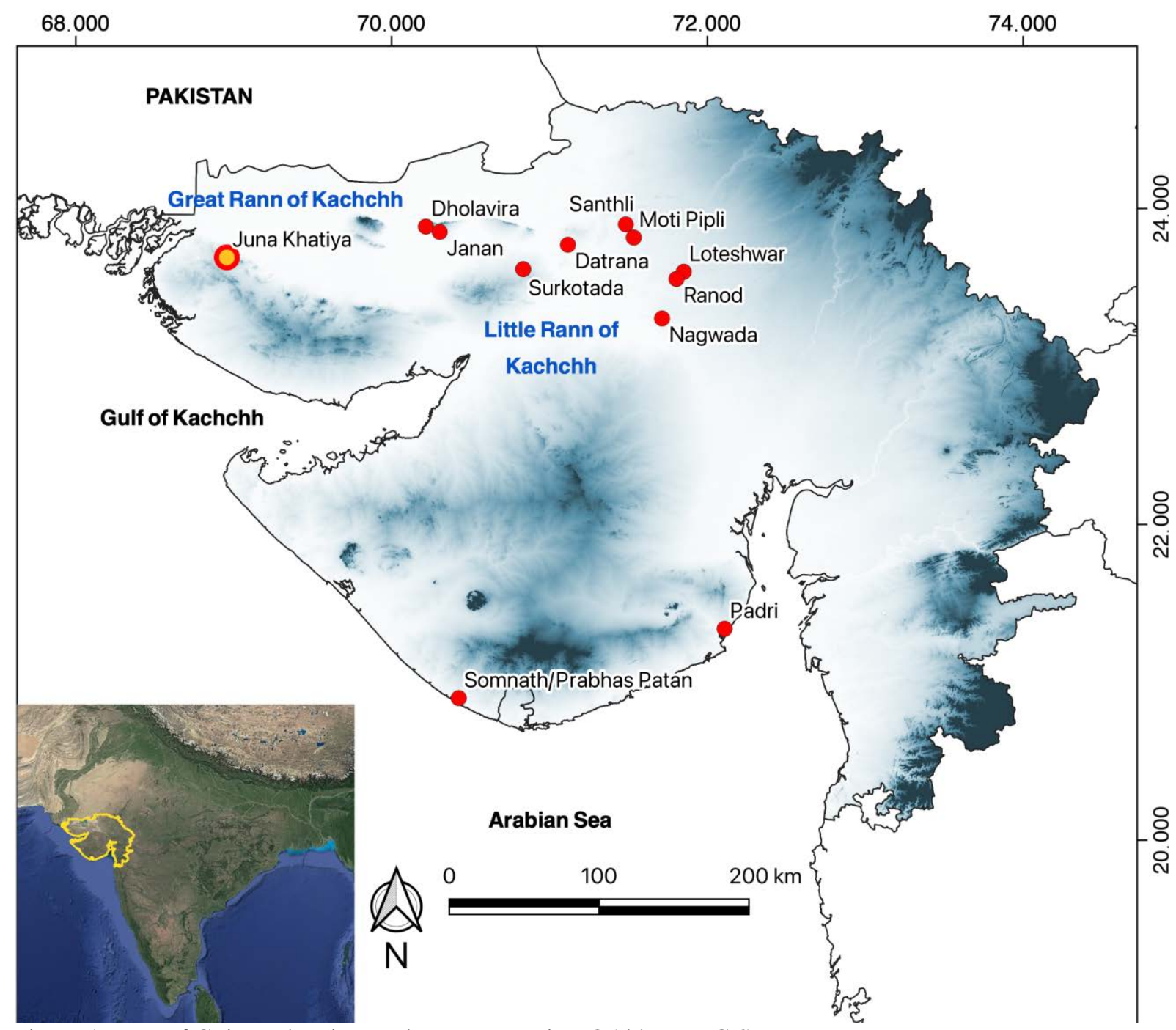

Figure 1: Map of Gujarat showing Early Harappan sites.@Abhayan, G.S.

As can be clearly observed from the above discussion, in studying Harappan Civilisation through its various material remains till date, emphasis has been put on the presence of different kinds or types of ceramic assemblages. This is due to the fact that changes in style and type of pottery occurred in response to social, economic and technical demands and for this reason pottery is closely integrated with the development of a civilisation. This approach though useful has its limitations, since it misses the importance of craft production and exchange in the Harappan economic set up. Study of specialized crafts which are thought to reflect the occupational specialization, urban segregation and stratification can throw a lot of light on the socio-political and economic structure of a civilisation (Kenoyer 1992). Study of craft items, including lithic blade tools is therefore important for a comprehensive understanding of cultural development.

The ceramic and lithic assemblages from Somnath, Datrana and Janan clearly show distinctive patterns. This pattern includes presence of regional as well as "external" ceramics (Pre-Prabhas-regional ceramic and Pre-Urban Harappan Sindh type ceramic) Rohri chert blades and evidence of crested ridge blade manufacturing technique (Ajithprasad 2002; Gadekar et al. 2018; Ghosh 1957). Rohri chert blades have always been given special 
treatment due to their exotic nature. These blades come from the Rohri hills in Pakistan and are unique in nature due their distinct colour and texture. The archaeological importance of these quarries and their association with the Indus Civilisation has been pointed out by several scholars (Allchin 1977, Biagi 2007, Biagi et al. 2018, Law 2008: 249). The wide distribution of standardised Rohri blades is often regarded as an index of the Harappan efficiency in long distance trade and craft production (Inizan \& Lechevallier 1995).

The presence of these artefacts establishes the fact that there was interaction between the coastal regions of Saurashtra, the interior North Gujarat, Kachchh all situated in modern day Gujarat, India and Sindh, modern Pakistan during the beginning of the third millennium BCE, about four or five centuries prior to the Urban Harappan phase. It is generally not very easy to obtain radiocarbon dates for sites in India due to financial restraints. However, the Early Harappan assemblage at Datrana have been dated to c. 3300-3000 BCE (please refer GarciaGranero et al. 2017 for further information regarding radiocarbon dates) and the Pre-Prabhas level at Somnath has provided a calibrated date of 2900 BC (Dhavalikar \& Possehl 1992).

Recent excavations and explorations at the site of Juna Khatiya have given similar evidence concerning its ceramic and lithic assemblages and have shown that Kachchh was definitely involved in a network of interaction during the late fourth and third millennium BCE.

\subsection{Juna Khatiya: An Early Harappan cemetery site}

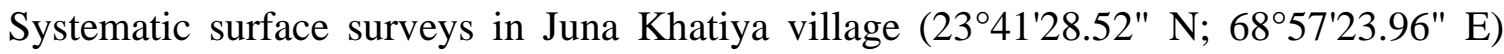
situated in Lakhpat Taluka, Kachchh District, Gujarat (Figure 1) by the archaeologists from University of Kerala, Thiruvananthapuram and KSKV Kachchh University, with financial support from the University of Kerala, have demonstrated cultural remains, irrefutable ceramic evidence, belonging to the Early Harappan phase of Indus Valley Civilisation. The site is located on the right bank of the river Gandi. The surface survey indicated burials without any clear evidence of habitation in the form of regular architectural remains. The surface collection yielded Early Harappan Sindh type pottery, stone blades of chalcedony, blade cores, geometric and non-geometric tools and a large amount of lithic debitage. The explorations revealed close to five hundred burials. The types of burials include extended inhumation, probable secondary burials, cremation and symbolic pot burials. The majority of the burials in the site were disturbed by erosion, soil removal and agricultural activities. A total of 70 (Figure 2) were excavated at the site. Many of the burial structures were made of stone (sandstone and shale) and vary in size and shape. Some of the burial remains were found in rectangular pits cut into natural soil. The burial goods found in the pits include pottery vessels, whose number varied from a single one to a maximum of nineteen. Many of the burial structures or pits were devoid of skeletal remains. The skeletons have not been carbon dated yet due to restricted funds.

\section{Material and methods}

\subsection{Classification of lithic assemblage}

The first step in the classification was the identification of different raw materials. All the raw materials belong to different types of crypto-crystalline siliceous materials which can be further classified into chalcedony, chert, banded agate, moss agate and quartz. Further classification of the lithic assemblages into finished tools and lithic debitage (the manufacturing waste) was done according to their morphological features. All the tools have been classified into 1) Blades-parallel sided flakes, generally double in length than their breadths, with either one or two mid-ridges (various types, explained below) and 2) 
Geometric and Non-geometric tools (after Gadekar 2015: 34, adapted from Sankalia 1964: 70-74).

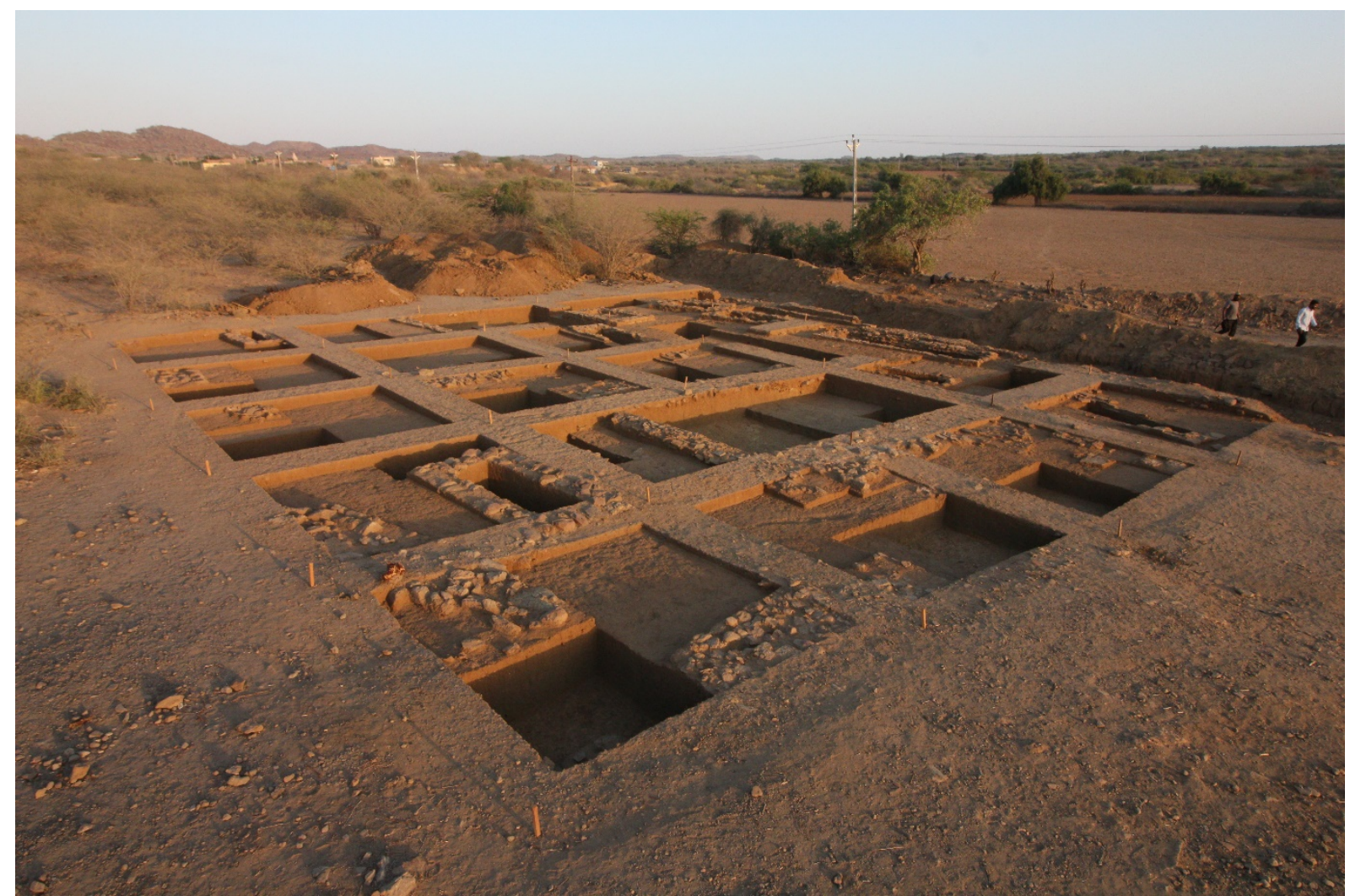

Figure 2: Excavated burials at Juna Khatiya (P.C. Department of Archaeology, University of Kerala)

1. Blades: Blades have been classified into simple blades (blades without any retouches but with edge damages or utilization marks on their lateral edges), backed blades (blades with retouches all along one longitudinal edge), crested ridge blades (flakes with evidence of manufactured crested ridge), retouched blades (blades showing minimal and irregular retouches) and blade flakes (blade like flakes with heavy edge damages but without parallel sides).

2. Geometric and non-geometric tools: A single lunate (a blade which has been retouched to give it the shape of a crescent. Usually, the arch is thick due to the retouches) represents the geometric tools. The non-geometric tools have been classified into points (blades with a pointed end achieved by retouching two marginal sides), endscrapers (a flake which has been retouched on one end, generally the distal end) to make it a tool), side scrapers (a flake with retouched marginal sides) and a notched scraper (a flake with retouching resembling a notch on one of the marginal sides).

Measurements of tools and debitage were taken by a digital calliper. Attributes recorded for all the tools, broken as well as intact, are the same. These include condition of tools (intact, broken-proximal, mesial, distal), cortex (absent or present, if present at what percentage, $<10 \%, 10-50 \%,>50 \%$ ), edge attributes such as retouches, backings and utilization marks (for both ventral and dorsal sides as well as left and right edges separately), description of platforms (proximal end characteristics such as type, shape and their measurements), condition of distal ends (feathered, stepped, plunging, hinged, retouched, snapped, used etc) and the number of dorsal ridges. All the measurements were taken by placing the tools with dorsal side facing the researcher and the proximal end facing up. The lengths correspond to a line perpendicular to the striking platform width for tools; the widths or breadths were taken 
at the mid- point of the length; thicknesses were measured by rotating the artefact $90^{\circ}$ from the width point. The lateral edges of all the blades were examined macroscopically.

Lithic debitage includes flakes (primary as well as secondary having a discernible point of applied force or striking platform), nodules, cores and waste fragment or the shatter (all flake debitage with no recognizable striking platform) (Andrefsky 2005: 16). Lithic debitage analysis follows a different method than tools. The intact and proximal flakes collected from the trenches during excavation were measured by placing them on a graph sheet and noting the closest value of $0.5 \mathrm{~cm}$ (adapted from Ahler 1989). All the lithic debitage collected while exploration was classified according to their raw materials and presence or absence of cortex. All the categories of lithic debitage were weighed. Any evidence of retouches or utilization on flakes, if found, were noted.

The cores, both blades and flakes, were analysed separately. The attributes recorded for cores closely follow the attributes recorded by Raczek (2010: 206). Length of cores was taken from the side of the removal of longest flake. Width of the core was measured keeping the flaked surface of the core (if it was flaked from one side) facing front. If it was a core which was flaked all over, the width was taken from the widest side. Thickness was measured by rotating the core $90^{\circ}$ from the position in which width was measured.

\section{Results}

The chipped stone assemblage at Juna Khatiya is represented by blades, geometric and non-geometric tools and fragments of lithic debitage. More than 95\% lithic assemblage was collected during surface exploration. Since the excavated trenches have neither yielded significant lithic assemblage nor shown a concentration of lithic material, the whole collection has been analysed as one unit.

\subsection{The blade assemblage}

The blade assemblage includes 444 blades, classified according to their attributes into simple blades (without any type of retouches), backed blades, retouched blades, crested ridge blades and blade flakes have been recovered from the site (Table 1 and Figure 3). 90\% of the blades were collected during surface exploration of the site, while the remaining blades belong to 16 excavated trenches. Most of the trenches do not show a concentration except trenches Le6 and Le8, where some concentration of blades can be observed.

Simple blades have been identified maximum in number from the assemblage. All the retouched blades, backed (uniform retouching of one marginal side) as well as randomly retouched (tools showing minor retouches on their marginal edges, have been classified as random since they are retouches, not use-marks which do not fall into other specified categories) constitute $4.95 \%$ while crested ridge blades are represented at $7.43 \%$ (Table 1 ). Since majority (418 or $94.14 \%$ ) of the blades was found in fragmentary condition they were further classified according to their fracture into proximal (No. 158), mesial (No. 216) and distal (No. 44) fragments. Majority of the blades are made out of chalcedony $(92.57 \%)$, followed by banded agate (6.53\%) (Table 1). More than $97 \%$ of the blades did not show presence of cortex. Secondary blades were selected intentionally to manufacture specialized tools, all the retouched blades were found to be without any cortex.

\subsection{Metric analysis of blades}

The purpose for this analysis is that intact specimens retain diagnostic characteristics that allow the investigator to record replicable measurements (Andrefsky 2005: 99). Metric analysis helps to understand standardisation, if present, in tools. 
Table 1: Classification of blades according to raw materials

\begin{tabular}{lcccccc}
\hline & \multicolumn{6}{c}{ Raw materials } \\
\cline { 2 - 5 } Blade types & Chert & Chalcedony & $\begin{array}{c}\text { Banded } \\
\text { agate }\end{array}$ & $\begin{array}{c}\text { Moss } \\
\text { agate }\end{array}$ & $\begin{array}{c}\text { Total } \\
\text { Number }\end{array}$ & Percentage \\
\hline Simple blades & 1 & 353 & 26 & 1 & 381 & $85.81 \%$ \\
Backed blades & 0 & 13 & 1 & 0 & 14 & $3.15 \%$ \\
Crested ridge blades & 0 & 31 & 2 & 0 & 33 & $7.43 \%$ \\
Blade flakes & 1 & 7 & 0 & 0 & 8 & $1.80 \%$ \\
Retouched blades & 1 & 7 & 0 & 0 & 8 & $1.80 \%$ \\
\hline Total (numbers) & $\mathbf{3}$ & $\mathbf{4 1 1}$ & $\mathbf{2 9}$ & $\mathbf{1}$ & $\mathbf{4 4 4}$ & $\mathbf{1 0 0 . 0 0 \%}$ \\
Percentage & $\mathbf{0 . 6 8 \%}$ & $\mathbf{9 2 . 5 7 \%}$ & $\mathbf{6 . 5 3 \%}$ & $\mathbf{0 . 2 3 \%}$ & $\mathbf{1 0 0 . 0 0 \%}$ & \\
\hline
\end{tabular}

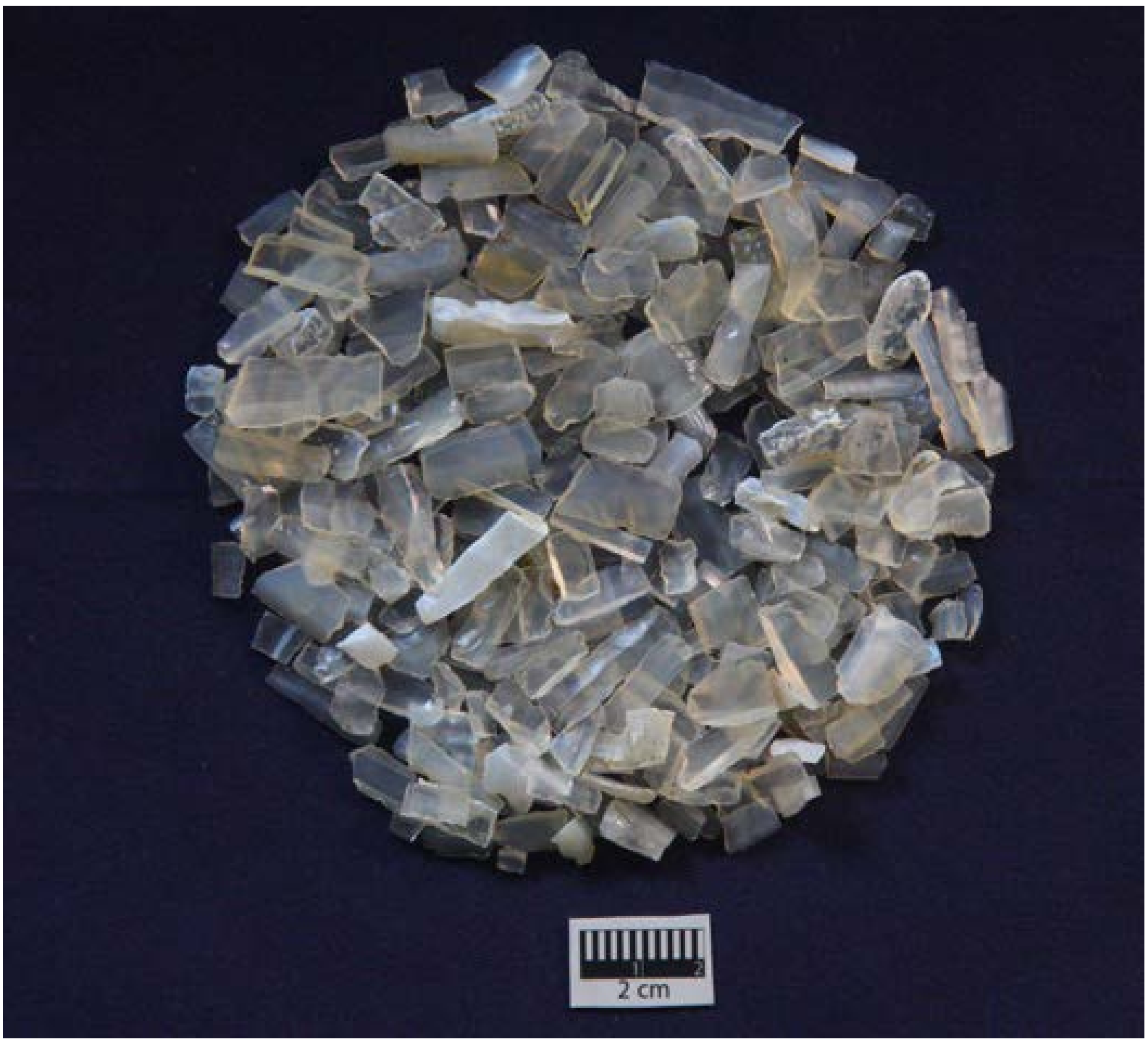

Figure 3: Various types of blades made out of Chalcedony (P.C. Department of Archaeology, University of Kerala).

Simple blades: The length values of intact blades and broken blades (taken separately), as expected, show variation in their sizes. Very little variation, however, was found amongst simple blades in their breadth and thickness values (Table 2). 
Table 2: Metric analysis of various blades (size in $\mathrm{mm}$ )

\begin{tabular}{|c|c|c|c|c|c|c|}
\hline & & & Mean & Median & Mode & Std. Dev. \\
\hline Simple & Intact blades (14) & Length & 26.14 & 25.56 & 15.48 & 8.32 \\
\hline \multirow{5}{*}{ blades } & & Breadth & 7.36 & 7.39 & 4.12 & 1.61 \\
\hline & & Thickness & 2.08 & 1.87 & 1.74 & 0.80 \\
\hline & Broken blades (418)* & Length & 12.78 & 12.16 & 12.15 & 4.52 \\
\hline & & Breadth & 7.31 & 6.94 & 6.39 & 1.81 \\
\hline & & Thickness & 1.99 & 1.85 & 1.39 & 0.74 \\
\hline \multirow{6}{*}{$\begin{array}{l}\text { Backed } \\
\text { blades }\end{array}$} & Intact blades (2) & Length & 25.39 & 25.39 & 23.47 & 2.72 \\
\hline & & Breadth & 7.24 & 7.24 & 6.63 & 0.86 \\
\hline & & Thickness & 2.53 & 2.53 & 2.07 & 0.65 \\
\hline & Broken blades (12) & Length & 13.62 & 13.23 & 7.18 & 4.96 \\
\hline & & Breadth & 7.44 & 7.06 & 6.39 & 1.34 \\
\hline & & Thickness & 2.42 & 2.39 & 2.54 & 0.75 \\
\hline \multirow{6}{*}{$\begin{array}{l}\text { Crested } \\
\text { ridge } \\
\text { blades }\end{array}$} & Intact blades (6) & Length & 17.25 & 15.84 & 12.97 & 4.97 \\
\hline & & Breadth & 13.73 & 10.07 & 6.48 & 9.99 \\
\hline & & Thickness & 3.21 & 2.73 & 2.18 & 1.35 \\
\hline & Broken blades (29) & Length & 14.22 & 13.46 & 8.76 & 3.86 \\
\hline & & Breadth & 7.83 & 7.55 & 4.7 & 2.21 \\
\hline & & Thickness & 3.01 & 2.67 & 2.2 & 1.13 \\
\hline \multirow{6}{*}{$\begin{array}{l}\text { Blade } \\
\text { flakes }\end{array}$} & Intact blades (6) & Length & 21.18 & 22.39 & 13.2 & 6.80 \\
\hline & & Breadth & 16.38 & 16.18 & 9.52 & 5.84 \\
\hline & & Thickness & 4.35 & 3.96 & 3.96 & 1.90 \\
\hline & Broken blades (2) & Length & 16.85 & 16.85 & 13.12 & 5.28 \\
\hline & & Breadth & 14.48 & 14.48 & 13.84 & 0.91 \\
\hline & & Thickness & 5.44 & 5.44 & 4.36 & 1.52 \\
\hline \multirow{3}{*}{$\begin{array}{l}\text { Retouched } \\
\text { blades }\end{array}$} & Broken blades (8) & Length & 12.96 & 12.81 & 6.85 & 5.32 \\
\hline & & Breadth & 8.29 & 7.69 & 5.92 & 2.14 \\
\hline & & Thickness & 2.41 & 2.31 & 1.57 & 0.51 \\
\hline
\end{tabular}

Backed blades: Backing of a blade is done intentionally by chipping an entire edge of the blade to facilitate in hafting as well as to increase the amount of force that could be applied to the worked material (Andrefsky 2005: 116; Montet-White 1988; Rule \& Evans 1985). As can be seen from Table 2, the backed blades show variation only in their length values, not in their breadth and thickness values. Similar breadth values of simple blades and backed blades suggest that most probably wider blades were being preferred for backing purposes. Small numbers of intact blades (Table 2) make them insignificant for any statistical analysis.

Crested ridge blades: These blades are the by-products of crested guiding ridge technique (Figure 4). The technique includes preparation of the core by making a longitudinal crested ridge which facilitates in the removal of parallel-sided blades (Evans 1897: 28; Sankalia 1967). Sankalia (1964: 35) has noted that this was the preferred technique to manufacture blades in 2nd and 3rd millennium BCE in South Asia. Their discovery from Juna Khatiya proves that people were well familiar with this blade manufacturing technique. Intact as well as broken crested ridge blades have been identified from the site. Intact blades appear to be longer and broader than the broken blades (Table 2). 


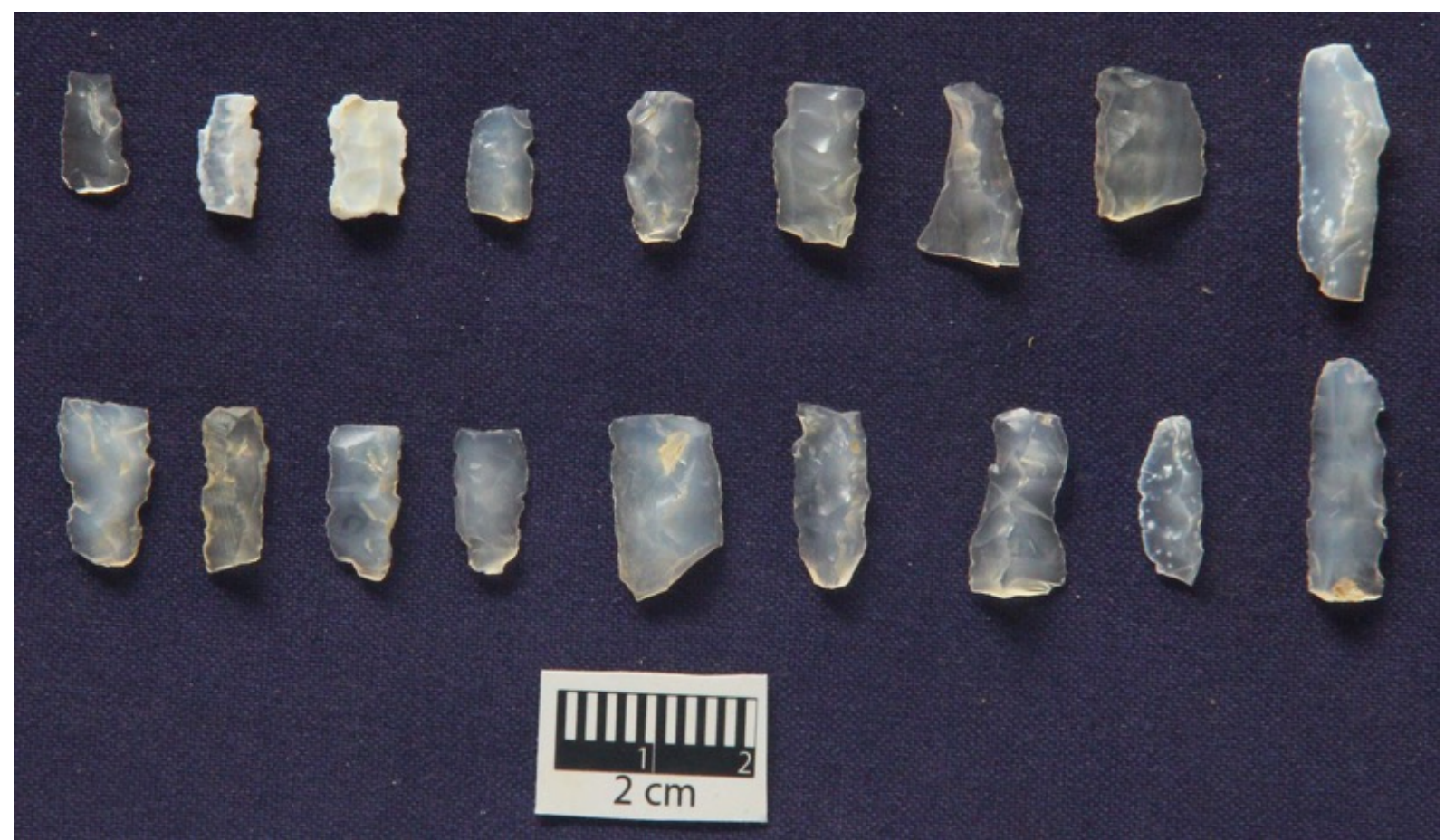

Figure 4: Crested ridge blades from Juna Khatiya (P.C. Department of Archaeology, University of Kerala)

Blade flakes: Eight heavily utilised blade flakes have been identified from the assemblage (Table 2).

Retouched blades: These blades have random retouches on their lateral edges which were most probably produced for hafting purposes. All the blades have been found in broken condition.

\subsection{Geometric and non-geometric tools}

Amongst the geometric category only one lunate was identified from the assemblage while in the non-geometric category points and different types of scrapers (Table 3) have been identified. Chalcedony was used to manufacture the majority of the tools (Table 3), though tools made out of banded agate, moss agate and chert have also been identified.

Table 3: Classification of tools according to raw material type

\begin{tabular}{lcccccc}
\hline & \multicolumn{6}{c}{ Raw Materials } \\
\cline { 2 - 5 } & Chert & Chalcedony & $\begin{array}{c}\text { Banded } \\
\text { agate }\end{array}$ & $\begin{array}{c}\text { Moss } \\
\text { agate }\end{array}$ & Total & Percentage \\
\hline Lunate & 0 & 0 & 1 & 0 & 1 & $4.76 \%$ \\
Points & 0 & 9 & 2 & 0 & 11 & $52.38 \%$ \\
Endscraper & 1 & 4 & 0 & 0 & 5 & $23.81 \%$ \\
Side scraper & 0 & 1 & 1 & 1 & 3 & $14.29 \%$ \\
Notched scraper & 0 & 1 & 0 & 0 & 1 & $4.76 \%$ \\
\hline Total & $\mathbf{1}$ & $\mathbf{1 5}$ & $\mathbf{4}$ & $\mathbf{1}$ & $\mathbf{2 1}$ & $\mathbf{1 0 0 . 0 0 \%}$ \\
Percentage & $\mathbf{4 . 7 6 \%}$ & $\mathbf{7 1 . 4 3 \%}$ & $\mathbf{1 9 . 0 5 \%}$ & $\mathbf{4 . 7 6 \%}$ & $\mathbf{1 0 0 . 0 0 \%}$ & \\
\hline
\end{tabular}

Lunate: Lunates have a large functional territory. Various scholars have hypothesised about their use as arrowheads and harpoon barbs (Sankalia 1964: 71), projectile points as well as cutting tools (Andrefsky 2005: 207). The single lunate identified from the assemblage measures $23.72 \mathrm{~mm}$ in length, $11.12 \mathrm{~mm}$ in breadth and $6.13 \mathrm{~mm}$ in thickness. This lunate has 
heavy lateral edge damage leading to the conclusion that it was most probably heavily utilised.

Points: 11 points have been identified from the assemblage (Figure 5). All, except one, were found to be in broken condition. The intact point measures $24.27 \mathrm{~mm}$ in length, $5.91 \mathrm{~mm}$ in breadth and $1.70 \mathrm{~mm}$ in thickness. The measurements of broken points (Table 4) show that these are very diverse in their lengths, however, their breadth and thickness values do not appear to vary significantly.

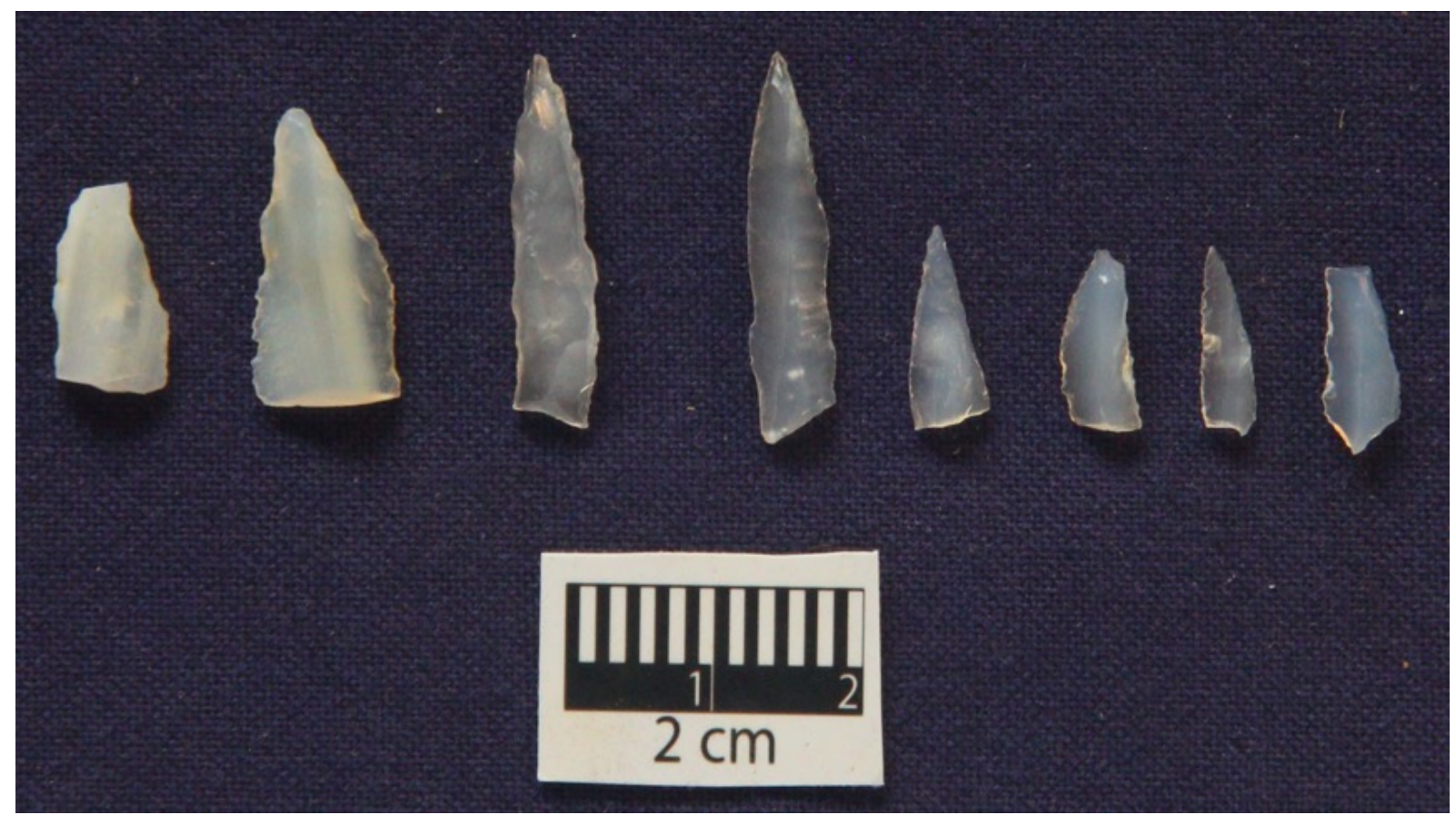

Figure 5: Points from Juna Khatiya (P.C. Department of Archaeology, University of Kerala)

Table 4: Metric analysis of tools

\begin{tabular}{llcccc}
\hline Tools & & Mean & Median & Mode & Std. dev. \\
\hline Points & Length & 13.64 & 12.42 & 8.26 & 4.26 \\
& Breadth & 6.16 & 5.67 & 3.64 & 1.82 \\
& Thickness & 2.32 & 2.26 & 1.09 & 0.86 \\
\hline \multirow{2}{*}{ Endscrapers } & Length & 15.23 & 14.01 & 10.6 & 5.44 \\
& Breadth & 19.34 & 17.27 & 11.35 & 10.56 \\
& Thickness & 5.39 & 3.44 & 2.26 & 3.70 \\
\hline Side scrapers & Length & 27.52 & 24.56 & 19.77 & 9.58 \\
& Breadth & 20.34 & 14.80 & 12.41 & 11.72 \\
& Thickness & 7.75 & 5.87 & 5.11 & 3.94 \\
\hline
\end{tabular}

Endscrapers: Five endscrapers were identified from the lithic assemblage. One was made out of chert while the other four were made out of chalcedony. All of them showed edge damage leading to the conclusion that they were utilized. Endscrapers are usually interpreted as scraping and working hide, bone, wood and antler (Andrefsky 2005: 206). Microwear studies have shown that end-scrapers could be used for graving, boring, chopping and also as projectiles (Odell 1981).

Side scrapers: Three side scrapers were identified amongst the assemblage. One was made out of chalcedony, one out of banded agate and one out of moss agate. Side scrapers are 
hypothesised to have been used for cutting, chopping, as projectiles and various combinations of these functions (Andrefsky 2005: 206).

Notched scraper: A scraper made out of chalcedony, with notches on both the edges was recovered from the assemblage. It measured $28.43 \mathrm{~mm}$ in length, $17.34 \mathrm{~mm}$ in its breadth and $4.09 \mathrm{~mm}$ in its thickness.

\subsection{Lithic debitage}

Lithic debitage or the by-products of stone tool productions from Juna Khatiya have been classified into primary flakes (950), secondary flakes (2690), core rejuvenation flakes (2), nodules (41), cores (81) and waste or shatter (70). Amongst the raw materials, chalcedony is represented at $94.8 \%$ followed by banded agate at $4.18 \%$. chert is represented at $0.56 \%$, quartz at $0.4 \%$, moss agate and carnelian are at $0.03 \%$.

Cores: A total of 81 blade cores have been found amongst the lithic assemblage (Figure 6). These have been classified into three shapes; conical (also known as fluted cores, these cores show removal of blades from all sides and have a conical shape), cylindrical (a core with blade removal from all the sides but have a cylindrical shape) and wedge (generally blades are removed only from one face of the core). The cores do not show a lot of similarity in their sizes, this could be due to various factors: the shape of the raw material, impurities of the raw material, the desire to utilize the raw material to its maximum capacity, the skill of the knapper, etc. (Table 5). 75 cores belong to raw material chalcedony, four belong to banded agate and two made of chert were identified from the assemblage. 48 cores were found intact while 33 cores were broken. Metric analysis has been conducted only for the intact cores (Table 5).

Blade removal pattern showed that a majority (no. 48) of the cores showed blade removal by slicing the core, 30 cores showed rotating the core to remove the blades while three cores had flexible removal of blades. It was also observed that majority of the cores (no. 76) showed unidirectional blade removal from the cores. Core platforms were mostly (no. 67) prepared by removing multiple tiny flakes from the surface. Five cores gave evidence of core rejuvenation process where it was clearly seen that a flake was diagonally removed to rejuvenate the platform. Majority of the cores (no. 5) showed absence of cortex.

There were also cores which showed presence of intact crested ridges either on their sides or on their backs. These cores indicate that each core may have utilized multiple initiation ridges. It has been hypothesized that providing multiple crested ridges on cores may have served to aide city-dwelling consumers who may have had less advanced blade production skills. Since it is easier to remove a blade from a prepared core than from an unworked nodule, preparing crested guided ridges before transport provided a service to consumers. That is, cores reached cities in a "ready-made" state (Raczek 2007: 157). This hypothesis, as yet untested, could be valid for big cities of Urban Harappan civilisation where core or blades were imported from Rohri hill quarries. But for small and rural Early Harappan sites such as Datrana (Gadekar et al. 2013), Janan (Gadekar et al. 2018) and now Juna Khatiya, this hypothesis appears to be invalid. Multiples crest preparation on large parent nodules appear to be a strategy to facilitate maximum utility of the nodule as it helps the knapper to utilize alternate ridges for successive blade removals even as one or more of the ridges become dysfunctional in the process of knapping. 


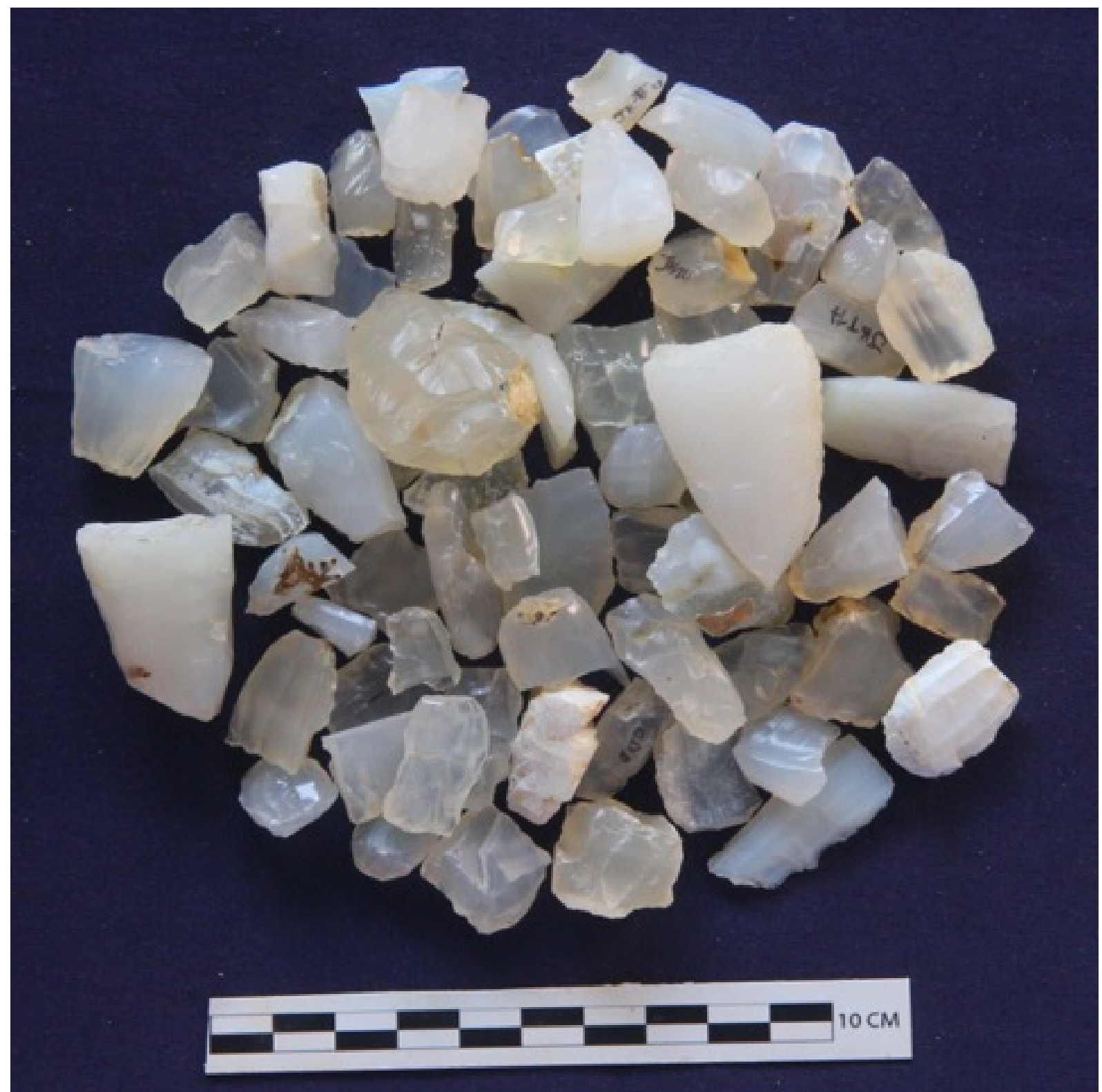

Figure 6: Blade cores from Juna Khatiya (P.C. Department of Archaeology, University of Kerala)

Table 5: Metric analysis of cores

\begin{tabular}{llcccc}
\hline Core shape & & Mean & Median & Mode & Std Dev \\
\hline Conical & Length & 28.27 & 25.96 & 16.07 & 9.55 \\
& Breadth & 17.72 & 18.17 & 9.21 & 6.54 \\
& Thickness & 10.73 & 9.18 & 3.99 & 5.5 \\
\hline Cylindrical & Length & 21.95 & 21.82 & 14.16 & 5.42 \\
& Breadth & 15.47 & 15.44 & 11.68 & 3.05 \\
& Thickness & 9.83 & 8.68 & 6.04 & 3.37 \\
\hline \multirow{2}{*}{ Wedge } & Length & 23.39 & 23.38 & 15.23 & 6.62 \\
& Breadth & 17.13 & 16.06 & 11.58 & 5.62 \\
& Thickness & 13.32 & 12.33 & 8.59 & 4.87 \\
\hline
\end{tabular}




\section{Discussion and conclusions}

The Early Harappan ceramic assemblages reported from habitational areas of sites such as Dholavira, Datrana, Moti Pipli and from burial sites such as Janan, Nagwada, Santhli, Surkotda and Dhaneti have given evidence of an early Chalcolithic phase. More and more such sites are being discovered in Gujarat and these are helping us to better understand the interaction between Sindh and Gujarat during the Early Harappan period. Understanding this interaction is crucial to understand the subsequent spread and development of the Indus Valley civilisation.

To date, Juna Khatiya, along with Datrana (Gadekar et al. 2013) and Janan (Gadekar et al. 2018, Rajesh et al. 2018), are the only Early Harappan sites in Gujarat from where the lithic assemblage has been analysed in detail. All three sites show evidence of Early Harappan burials along with evidence of a knapping technology well known to Early Harappans of Sindh viz. crested guiding ridge technique. This technique has been found to be well developed in the Early Harappan sites of Sindh and Baluchistan region (Peprino 1973) and is not encountered from any of the cotemporary regional sites of Gujarat. Thus, the discovery of this technique along with Early Harappan pottery clearly indicates a give and take between craftsmen of two contemporary regions.

It is also noteworthy how the lithic assemblages are comparable in terms of typology, which most probably indicates similar functions, a topic not yet explored. All three sites have given evidence of various types of blades (backed blades, retouched blades, blade flakes), very few geometric tools and scrapers but a good quantity of points. The main raw material utilized for manufacturing the tools was chalcedony, locally available near the sites. By a careful macro-observation of the edge damage, it has been hypothesised that majority of the finished tools were heavily utilized. The presence of crested guiding ridge blades, cores with intact crested guiding ridges and other lithic debitage strongly suggest that the tools were manufactured at the sites. Distinctive and indisputably chert blades made out of raw material only available at the Rohri hills in modern Pakistan have also been identified from all three sites. These were mostly found in broken condition. Lack of lithic debitage of this raw material affirms that they were imported and not manufactured at the sites. Resemblances between these sites suggest some homogeneity (hallmark of Indus Valley Civilisation) even during the Early Harappan phase. The presence of crested guiding ridge technique from these sites have led us to believe that even when people are familiar with several alternatives for manufacturing craft items like blades, they would persist in following the technological traditions of their community (Weissner 1984). And these technological practices common to craft specialists has provided evidence for tracing network links. Thus, the study of technological traditions among specialists can, and in this case has, indicated bridges between communities and across social boundaries (Hegmon 1998; Stark 1998).

At Juna Khatiya the artefacts appear to be contemporary to the burials. The burials have been dated to the Early Harappan period based on the relative ceramic assemblage. The lithic assemblage is comarable (typologically and technologically) to the assemblage recovered from the site of Datrana, radio carbon dated to the Early Harappan period (Garcia-Granero et al. 2015). Thus, making the lithic artefacts contemporary to the burials. This simultaneous existence of a blade manufacturing area and a burial ground is puzzling. Three scenarios have been hypothesized.

1. The tools were already present at the site before the burials (belonging to a regional Chalcolithic tradition). Here the fact that the crested guiding ridge has not been observed in Gujarat prior to the advent of the Pre-Harappan phase has to be kept in mind.

2. The site was occupied by people who manufactured lithic tools for a short period of time before converting the place into a cemetery. 
3. Tools were being manufactured at the same time as the burials were being made. The burials must have been formed over a long period of time.

Since the tools are found from both the surface of the site as well as from inside the burials, it appears that the authors of burials as well as the lithic tools, were the same group of people (personal communication with Prof. P. Ajithprasad on $9^{\text {th }}$ May, 2019). Production of tools parallel to the burials would appear strange; however, it should be kept in mind that a particular area of the site might have been the designated tool production area and due to site forming activities there is a mixture of records. It should also be kept in mind that majority of the lithic assemblage was recovered from the surface, not the actual burials.

Further excavations and explorations in the surrounding area to find a habitational site, identifying the geographical areas for the raw materials utilized, identifying a route through which Early Harappans might have reached this area, identifying the geographical identity of the people buried in the burials, etc. will be helpful to answer questions regarding the interactions between Early Harappan communities of Sindh and Gujarat.

\section{Acknowledgements}

We are very thankful to the anonymous reviewers for their comments and have tried our best to incorporate as many improvements as were possible. The first author (CG) is thankful to Dr. Sanghamitra Desai Gadekar for her help and support during the data collection at the site and to Prof. P. Ajithprasad for insightful discussions after the analysis. CG also acknowledges current funding from the European Union's Horizon 2020 research and innovation programmer under the Marie Sklodowska-Curie Action-Individual Fellowships, grant number 891238. The authors are thankful to the Archaeological Survey of India and the Department of Archaeology, Gujarat State for granting exploration and excavation permission, the University of Kerala for giving funds and to the people of Juna Khatiya village for their hospitality and students of University of Kerala and KSKV University, Bhuj for their help during field work. We are thankful to the help provided by Mr. Mitul Zaveri from Karma Construction Bhuj for DGPS Survey and Mr. Jaymeet Solanki for the Drone Survey.

\section{Data accessibility statement}

The authors confirm that the data supporting the findings of this study are available within the article.

\section{References}

Ahler, S.A. 1989, Mass analysis of flaking debris: Studying the forest rather than the trees. In: Alternative Approaches to Lithic Analysis (Henry, D.O. \& Odell, G.H., Eds.), American Anthropological Association, Virginia: p. 85-118. doi:10.1525/ap3a.1989.1.1.85

Ajithprasad, P. 2002, The Pre-Harappan cultures of Gujarat. In: Indian Archaeology in Retrospect (Settar, S. \& Korisettar, R., Eds.), Vol. II Protohistory: Archaeology of the Harappan Civilisation, Manohar Publishers and Distributors, New Delhi: p. 129-158.

Ajithprasad, P. 2004, Holocene adaptations of the Mesolithic and Chalcolithic settlements in North Gujarat. In: Monsoon and Civilisations (Yasuda, Y. \& Shinde, V., Eds.), Roli Books, New Delhi: p. 115-132. 
Ajithprasad, P. 2011, Chalcolithic cultural patterns and the Early Harappan interaction in Gujarat. In: Cultural Relations between the Indus and the Iranian Plateau during the Third Millennium BCE, (Osada, T. \& Witzel, M., Eds.), Harvard Oriental Series Opera Minora Vol.7, Department of South Asian Studies, Harvard University: p. 11-40.

Allchin, B. 1977, Hunter, Pastoralists and early Agriculturalists in south Asia. In: Hunters, Gatherers and the First Farmers Beyond Europe (Megaw, J.V.S., Ed.), Leicester University Press, Leicester: p. 127-143.

Andrefsky, W.J. 2005, Lithics: Macroscopic Approached to Analysis. Cambridge University Press, Cambridge, 301 p. doi:10.1017/CBO9780511810244

Biagi, P. 2007, Quarries in Harappa. In: Encyclopaedia of the History of Science, Technology and Medicine in Non-Western Cultures 2 (Selin, H., Ed.), Springer Verlag, BerlinHeidelberg: p. 1856-1863. doi:10.1007/978-1-4020-4425-0 9696

Biagi, P, Starnini, E. \& Michniak, R. 2018, Chert mines and Chert miners. The Material Culture and Social Organization of the Indus Chipped Stone Workers Artisans and Traders in the Indus Valley (Sindh, Pakistan). In: Walking with the Unicorn-Jonathan Mark Kenoyer Felicitation Volume (Frenez, D., Jamison, G., Law, R., Vidale, M. \& Meadow, R. Eds.), Archaeopress, Oxford: p. 68-89. doi:10.2307/j.ctv19vbgkc.11

Dhavalikar, M.K. \& Possehl, G.L. 1992, The Pre-Harappan Period at Prabhas Patan and the Pre-Harappan Phase in Gujarat. Man and Environment, 17(1): 72-78.

Evans, J. 1897, The ancient stone implements, weapons and ornaments of Great Britain. 2nd ed., Longmans, Green, and Co., London and Bombay, 709 p.

Gadekar, C. 2015, Lithic blade implements and their role in the Harappan Chalcolithic cultural development in Gujarat. Ph.D. Thesis at the Department of Archaeology and Ancient History, The M.S. University of Baroda, Vadodara, India, 262 p. URL: http://hdl.handle.net/10603/56193

Gadekar, C., Ajithprasad, P., \& Madella, M. 2013, Crested ridge technique and lithic assemblage from Datrana, Gujarat. Heritage: Journal of Multidisciplinary Studies in Archaeology, 1: 16-28. doi:10.2218/jls.v1i1.764

Gadekar, C., Rajesh, S.V., Abhayan, G.S., Prakash Sharma, B., Ajithprasad, P., Kumar, A., Chase, B., Rawat, Y.S., Patel, A., Muhammed Fasalu, K., Dev, A.V., Haseen Raja R., Kumbodharan, S., Vinuraj, B., Arun Kumar, K.S., Mahesh, M.S., Gobinsingh, S.M. \& Mohammed Muhaseen, B.S. 2018, Typo-technological analysis of lithic assemblage from Janan, Kachchh, Gujarat. Man and Environment, 43(1): 6-15.

Garcia-Granero, J.J., Gadekar, C., Esteban, I., Lancelotti, C., Madella, M. \& Ajithprasad, P. 2017, What is on the craftsmen's menú? Plant consumption at Datrana, a 5000-year-old lithic blade workshop in North Gujarat, India. Archaeological and Anthropological Sciences, 9: 251-263. doi:10.1007/s12520-015-0281-0

Ghosh, A., (Ed.), 1957, Indian Archaeology-A Review, 1956-57. Department of Archaeology, Government of India, New Delhi, 183 p.

URL: http://nmma.nic.in/nmma/nmma_doc/Indian\%20Archaeology\%20Review/Indian \%20Archaeology\%201956-57\%20A\%20Review.pdf

Hegmon, M. 1998, Technology, style and social practices: Archaeological approaches. In: The Archaeology of Social Boundaries (Stark, M.T. Ed.), Smithsonian Institution Press, Washington and London: p. 264-279 
Inizan, M.-L. \&. Lechevallier, M.A. 1995, Transcultural Phenomena in the Chalcolithic and Bronze Age Lithics of the Old World: Raw Material Circulation and Production of Standardized Long Blades. In: The Example of the Indus Civilization (Allchin, B. \& Allchin, F.R. Eds.), South Asian Archaeology. Ancient India and Iran Trust, New Delhi: p. 77-85.

Kenoyer, J.M. 1992, Harappan Craft Specialization and the Question of Urban Segregation and Stratification. Eastern Anthropologist, 45(1-2): 39-54

Lahiri, N. 2017, Are archaeological discoveries like scientific discoveries? The curious case of the Indus Civilization. World Archaeology, 49(2): 174-186 doi:10.1080/00438243.2016.1264310

Law, R.W. 2008, Inter-Regional Interaction and Urbanism in the Anceint Indus Valley: A Geological Province Study of Harappa's Rock and Minaral Assemblage. Ph.D. Dissertation no. Ocn302421826 at the University of Wisconsin-Madison, Madison, $1147 \mathrm{p}$.

Mehr, S.S. 1995, Geology of Gujarat. Geological Society of India, Bangalore, 222 p.

Montet-White, A. 1988, Raw material economy among medium-sized Late Paleolithic campsites of Central Europe. In: Upper Pleistocene Prehistory of Western Eurasia (Dibble, H.L. \& Montet-White, A. Eds.), University Museum Monograph 54. University of Pennsylvania, Pennsylvania: p. 361-374.

Odell, G.H. 1981, The morphological express at Function Junction: searching for meaning in lithic tool types. Journal of Anthropological Research, 37: 319-342. doi:10.1086/jar.37.4.3629831

Patel, A.K. 2008, New radiocarbon Determinations from Loteshwar and their implications for understanding Holocene settlement and subsistence in North Gujarat and adjoining areas. In: South Asian Archaeology 1999 (Raven, E.M. Ed.), Egbert Forsten, Groningen: p. $123-134$.

Peprino, M. 1973, Micro-drilling at Shahr-i-Sokhta: The making and use of the lithic drillheads. In: South Asian Archaeology, First International Conference of South Asian Archaeologists (Hammond, N. Ed.), University of Cambridge, Cambridge: p.119-130.

Raczek, T.P. 2007, Shared histories: Technology and community at Gilund and Bagor, Rajasthan, India (c.3000-1700 BC). Ph.D. Dissertation no. AAI3292066 at the Department of Anthropology, University of Pennsylvania, Philadelphia: 378 p.

Raczek, T.P. 2010, Contextualizing Gilund: A Comparative Analysis of Technology. In: The Gilund Project: Excavations in Regional Context. Proceedings of the $19^{\text {th }}$ Meeting of the European Association of South Asian Archaeology in Ravenna, Italy, July 2007 (Raczek, T.P. \& Shinde, V. Eds.), South Asian Archaeology 2007: Special sessions 2; BAR International Series 2132. Archaeopress, Oxford: p. 33-40.

Rajesh S.V., Gadekar, C., Abhayan G.S., Ajithprasad, P. \& Sharma, B.P. 2018, Janan- A PreUrban Harappan site on Khadir Island, Kachchh district, Gujarat. Puratattva, 48: 173183.

Rajesh, S.V. 2012, A comprehensive study of the regional Chalcolithic cultures of Gujarat. Ph.D. Dissertation at the Department of Archaeology and Ancient History, The Maharaja Sayajirao University of Baroda, Vadodara, India, 714 p.

URL: http://hdl.handle.net/10603/72819 
Rule, P. \& Evans, J. 1985, The relationship of morphological variation to hafting techiques among Paleoindian endscrapers at the Shawnee Minisink Site. In: Shawnee Minisink: A Stratified Paleoindian-Archaic Site in the Upper Delaware Valley of Pennsylvania (McNett, C., Ed.), Academic Press, New York: p. 211-220. doi:10.1016/B978-0-12485971-5.50014-3

Sankalia, H.D. 1964, Stone Age Tools: Their Techniques, Names and Probable Functions, Building Centenary and Silver Jubilee Series 1. Deccan Collage Postgraduate and Research Institute, Poona, 114 p.

Sankalia, H.D. 1967, The Socio-economic Significance of the Lithic Blade Industry of Navdatoli, Madhya Pradesh, India. Current Anthropology, 3: 262-268. doi:10.1086/200803

Shaffer, J.G. 1992, The Indus Valley, Baluchistan and Helmand Traditions: Neolithic through Bronze Age. In: Chronologies in Old World Archaeology (Ehrich, R.W., Ed.), University of Chicago Press, Chicago: Vol. 1: 441-464, Vol. 2: 425-446.

Shinde, V. 1992a, Excavations at Padri 1990-91: A preliminary report. Man and Environment, 17(1): 79-86.

Shinde, V. 1992b, Padri and the Indus Civilisation. South Asian studies, 14: 173-182. doi:10.1080/02666030.1998.9628559

Stark, M.T. 1998, Technical choices and social boundaries in material culture patterning: An introduction. In: The Archaeology of Social Boundaries (Stark, M.T., Ed.), Smithsonian Institution Press, Washington and London, p. 1-11.

Weissner, P. 1984, Reconsidering the behavioural basis for style: A case study among the Kalahari San. Journal of Anthropological Archaeology, 3: 190-234. doi:10.1016/02784165(84)90002-3

Wright, R. 2009, The Ancient Indus: Urbanism, Economy and Society. Cambridge University Press, Cambridge, 418 p. 